\title{
Effect of Using Online Active Instructional Model to Enhance Learning Behaviors of Undergraduate Students
}

\author{
Jirapha Autthaporn and Prakob Koraneekij
}

\begin{abstract}
This research has an objective to study the effect of using online active instructional model to enhance learning behaviors of undergraduate students. The sample of the research comprises 30 undergraduate students from the Faculty of Education, Chulalongkorn University. The research tools include the plan for the organization of learning activities, the website regarding active instruction as well as the plan for the provision of instruction. The equipments used in the data collection are the observation form to examine students' learning behaviors, the criteria for the assessment of the quality of students' works by rubrics and the questionnaire to survey opinions on online active instructions. Mean, standard deviation and one-way repeated measure ANOVA are used in the data analysis.

The results of the study revealed that the sample's learning behaviors in each week increased with the statistical significance of $\mathbf{. 0 5}$.
\end{abstract}

Index Terms-Online learning, active instruction, learning behavior.

\section{INTRODUCTION}

Active instruction focuses on producing active learners rather than passive learners, which can be encouraged by the methods of active instruction. According to the research by Sweller (2006) [1], it was discovered that active instruction suits the objectives of learning for understanding and the application of knowledge in daily life, and that it stimulates students' enthusiasm to learn and to think more efficiently than the method of learning by heart alone. Active learning, therefore, is the instruction which helps to enhance the efficiency of students' learning achievement. Students will be satisfied with the form of instruction which allows them to participate in active learning rather than passive learning when they only have to sit and wait for the knowledge. Such idea is in accordance with that of Renner and Abraham (2008) [2] which pointed out that the organization of learning activities which enables learners to gain the accurate, profound and permanent knowledge and understanding of the concepts that are taught, to proficiently connect the knowledge, to enjoy the learning activities and to be able to integrate the knowledge from the instruction and make it useful is the result from the learning which allows students to take action in the activities by themselves.

Regarding the accurate and appropriate application of

Manuscript received August 13, 2014; revised October 15, 2014.

The authors are with the Department of Educational Technology and Communications, Faculty of Education, Chulalongkorn University, Bangkok 10330, Thailand (e-mail: oillio01@ hotmail.com). information technology for the development of distance education both domestically and internationally, the internet is considered the world's largest knowledge resource [3]. Online learning encourages learners to become valuable teaching resources. In traditional instruction, educational resources are determined by the number of students. More students cause the use of limited educational resources to be spared. On the other hand, online teaching and learning stimulates students to learn by themselves according to the constructivist learning philosophy. The use of online learning technology for education is considered useful both in terms of convenience and development of students' learning efficiency. The creation of social network and interaction in the management of this form of instruction is superior to that of normal classrooms in terms of learning efficiency and expansion of educational opportunities which respond to the needs of each learner [4].

The main issues as mentioned above caused the researcher to study related theories and researches and finally discovered the developed pattern which comprises 9 elements as follow: 1) instructors' roles; 2) learners' roles; 3 ) instruction system; 4) contents of lessons; 5) learner-centered teaching; 6) communication through technologies; 7) process to encourage learning behaviors; 8) reflection of students' learning and 9) measurement and assessment. The pattern of online active instruction to enhance learning behaviors consists of 5 steps, which are: 1) the study; 2) the connection of problems; 3) the brainstorming; 4) the observation and 5) the reflection. Such process is the development of online active instruction pattern in response to the learning skills of the 21th century regarding the use of technology in teaching and learning to allow learners to integrate knowledge and develop learning vision by combining knowledge, specific skills, proficiency and awareness of various aspects altogether. The objective is to enable learners to gain achievement both in working and living and also to use the pattern as the model of online active instruction, which can be applied in the teaching and learning process in the future. Thus, it is considered the new start of future skill development for Thailand.

\section{OBJECTIVE OF THE RESEARCH}

The objective of this research is to study the effect of using online active instructional model to enhance learning behaviors of undergraduate students.

\section{RESEARCH HYPOTHESIS}

The students who learn by using the online active 
instructional model to enhance learning behaviors of undergraduate students have better learning behaviors in each week with the statistical significance of .05.

\section{RESEARCH METHOD}

The experiment on the instructional model will be carried out in the form of experimental design which is the one group posttest only design. The research methods are as follow:

- To study the documents and researches which are related to active instruction, online learning and learning behaviors of students.

- To determine the population and select the sample group.

- To study related theories and researches to create research equipments.

- To design the experiment and conduct the experiment with the sample group.

- To compile data, analyze data and discuss the results.

\section{RESEARCH SAMPLE}

The sample of this research comprises 30 undergraduate students from the Faculty of Education, Chulalongkorn University who registered in the subject of 2726207 Educational Technology and Information (Practical Section) in the $2^{\text {nd }}$ semester of the academic year 2013.

\section{RESEARCH TOOLS}

\section{A. The Tools Used in the Experiment Are}

The first tool is the plan for the organization of learning activities of the subject 2726207 Educational Technology and Information (Practical Section) and the process of online active instruction to enhance learning behaviors of undergraduate students. The learning hours totaled 2 hours per week, and the experiment period totaled 7 weeks. According to the assessment by 3 experts, it was discovered that the index of objective congruence (IOC) was between $0.8-1.0$, which meant that the plan for the organization of learning activities was suitable in terms of content, application for instruction provision as well as learning measurement and assessment.

The second tool is the online active instructional model to enhance learning behaviors of undergraduate students which comprises 9 elements as follow:

1) instructors' roles; 2) learners' roles; 3) instruction system; 4) contents of lessons; 5) learner-centered teaching; 6) communication through technologies; 7) process to encourage learning behaviors; 8) reflection of students' learning and 9) measurement and assessment. The instructional process consists of 5 steps, which are: 1) the study; 2) the connection of problems; 3 ) the brainstorming; 4) the observation and 5) the reflection. The online active instructional model to enhance learning behaviors of undergraduate students has been assessed by 5 experts who investigated the suitability of the model using 5 rating scale. The result from the assessment showed that the suitability of the model was at very good level.

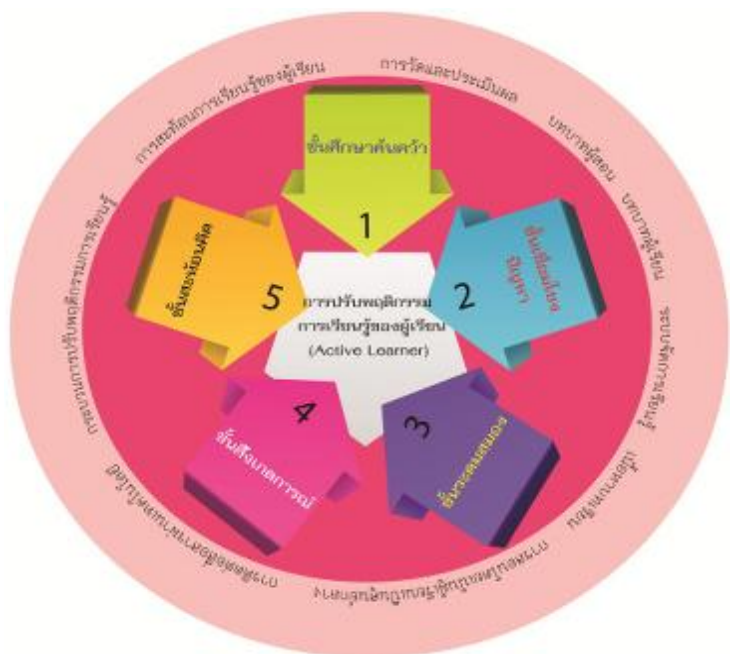

The online active instructional model to enhance learning behaviors of undergraduate students

The third tool is the website regarding active instruction, which is the instructional program that is the center of active instruction for the observation and recording of students' learning behaviors. This tool will enable both learners and instructors to access the content and use it easily with the help of equipments for management, control improvement, data backup, data support, students' record and assessment. Students have to log in to the instructional system every time while instructors have to take care of the system and examine the traces of students' learning behaviors through the instructional system. Regarding the assessment, 3 experts evaluated the system using 5 rating scale. The result of the assessment was at Level 4, which meant that the suitability of the LMS instructional system was at good level.

\section{B. Equipments Used for Data Collection Are as Follow}

The first equipment is the test to measure learning achievement of students. The test was used with the students whose characteristics resembled those of 30 students in the sample group. Afterwards, the results were utilized in the analysis of the disciminant index, the difficulty index of each item and the reliability of the test. It was found out that the difficulty index (p) and the disciminant index (r) of the posttest were in accordance with the criteria, i.e., the difficulty indices were between $0.2-0.8$ and the disciminant indices were from 0.2 onwards. When the reliability was analyzed using the KR-20 formula by Kuder-Richardson, it was discovered that the reliability was at 0.78 .

The second equipment is the criteria for the assessment of students'works by rubrics. After the criteria were created, 3 experts examined the quality of the criteria for the assessment of students' works by rubrics. The content validity, the language accuracy and the suitability of the criteria were examined. The result of the quality examination by experts using 5 rating scale revealed that the suitability was at very good level.

The third equipment is the observation form to examine the learning behaviors of students who were taught using the online active instructional model to enhance learning behaviors of undergraduate students. The observation form which had been created was examined by 3 experts who investigated the content validity, the completeness and the 
ambiguity of the questions. It was found out that the suitability was at very good level.

\section{DATA COLLECTION}

Week 1 (before the experiment): The equipments and the locations for the experiment were prepared. Then, the instructor offered the orientation to students by informing them about the objectives of instruction, demonstrating the steps of instruction and making an appointment for the instruction in the following week.

Week 2 - Week 6 (during the experiment): The students carried out the learning activities according to the 5 steps of the online active instruction and submitted assignments in each week continually. Afterwards, the instructor collected the data as follow:

The assessment of students' working scores according to the rubrics evaluation criteria.

The assessment of students' learning behaviors by observing the traces of their works in each week from the hints found on the LMS learning system.

Week 7 (after the experiment): The students took a posttest to measure their learning achievement. Also, the students completed their self-evaluation form after learning. The instructor assessed the overall learning behaviors of the students after learning and gave them feedback.

\section{DATA ANALYSIS}

The data were analyzed using frequency, percentage, mean and standard deviation to explain general information.

The data were analyzed using mean and standard deviation to measure the learning achievement of the sample group after learning.

The data regarding students' learning behaviors were analyzed using descriptive statistic. Frequency, percentage, mean and standard deviation were used for the explanation of data from the observation form which examined students' learning behaviors.

The data regarding one-way repeated measure ANOVA) were analyzed in the explanation of data derived from the works' quality scores.

\section{RESUltS OF THE RESEARCH}

The results of the research on the effect of using online active instructional model to enhance learning behaviors of undergraduate students are as follow:

The results of data analysis showed the scores of the sample group's learning behaviors in various aspects, which were the access to instructional system, the period of time spent for the access of instructional system, the interaction between the students on the instructional system, the interaction between the students and the instructor on the instructional system, the submission of assigned tasks and the relationship between the period of time spent for the access of system and the learning results of the students in Week 1, Week 3 and Week 5.

According to the details about the access to instructional system, it was discovered that, in Week 1, 29 students from the sample group had the access to instructional system, which were considered 96.6\%. In Week 3, 29 students from the sample group had the access to instructional system, which were considered $96.6 \%$. In Week 5, 30 students from the sample group had the access to instructional system, which were considered $100 \%$ (see Table I).

TABLE I: ACCORDING TO THE DETAILS ABOUT THE ACCESS TO INSTRUCTIONAL SYSTEM

\begin{tabular}{|c|c|c|c|}
\hline \multirow{2}{*}{\multicolumn{2}{|c|}{ Detail }} & \multicolumn{2}{|c|}{$n=30$} \\
\hline & & $\begin{array}{l}\text { number } \\
\text { (person) }\end{array}$ & $\%$ \\
\hline $\begin{array}{l}\text { Access } \\
\text { system }\end{array}$ & to instructional & & \\
\hline Week 1 & & 29 & 96.6 \\
\hline Week 3 & & 29 & 96.6 \\
\hline Week 5 & & 30 & 100 \\
\hline
\end{tabular}

According to the details about the period of time spent for the access of instructional system, it was found out that, in Week 1, 14 students from the sample group spent 0-50 minutes for the access of instructional system, which were considered $46.6 \%$; 10 students spent 51-100 minutes, which were considered $33.4 \%$; 3 students spent 101-150 minutes, which were considered $10 \%$ and 3 students spent over 150 minutes, which were considered $10 \%$. In Week 3,13 students from the sample group spent 0-50 minutes for the access of instructional system, which were considered $43.3 \% ; 12$ students spent 51-100 minutes, which were considered $40 \%$; 3 students spent 101-150 minutes, which were considered $10 \%$ and 2 students spent over 150 minutes, which were considered $6.7 \%$. Finally, in Week 5, 20 students from the sample group spent 0-50 minutes for the access of instructional system, which were considered $66.6 \%$ and 10 students spent 51-100 minutes, which were considered $33.4 \%$ (see Table II).

TABLE II: ACCORDING TO THE DETAILS ABOUT THE PERIOD OF TIME SPENT FOR THE ACCESS OF INSTRUCTIONAL SYSTEM

\begin{tabular}{ccc}
\hline & \multicolumn{2}{c}{$n=30$} \\
\cline { 2 - 3 } Detail & $\begin{array}{l}\text { Number } \\
\text { (Person) }\end{array}$ & $\%$ \\
\hline
\end{tabular}

\section{Period of time spent for the} access of instructional system

Week 1

\begin{tabular}{rcc}
$0-50$ minutes & 14 & 46.6 \\
$51-100$ minutes & 10 & 33.4 \\
$101-150$ minutes & 3 & 10 \\
Over 150 minutes & 3 & 10 \\
\hline Total & $\mathbf{3 0}$ & $\mathbf{1 0 0}$
\end{tabular}

\begin{tabular}{|c|c|c|}
\hline & & \\
\hline \multicolumn{3}{|l|}{ Week 3} \\
\hline $0-50$ minutes & 13 & 43.3 \\
\hline $51-100$ minutes & 12 & 40 \\
\hline $101-150$ minutes & 3 & 10 \\
\hline Over 150 minutes & 2 & 6.7 \\
\hline Total & 30 & 100 \\
\hline \multicolumn{3}{|l|}{ Week 5} \\
\hline $0-50$ minutes & 20 & 66.7 \\
\hline $51-100$ minutes & 10 & 33.3 \\
\hline 101 - 150 minutes & 0 & 0 \\
\hline Over 150 minutes & 0 & 0 \\
\hline Total & 30 & 100 \\
\hline
\end{tabular}


According to the details about the interaction between the students on the instructional system (expression of opinions), it was discovered that, in Week 1, 28 students from the sample group had mutual interaction with other students on the instructional system in terms of expression of opinions, which were considered 93.3\%. In Week 3, 27 students from the sample group had mutual interaction with other students on the instructional system in terms of expression of opinions, which were considered $90 \%$. In Week 5, 30 students from the sample group had mutual interaction with other students on the instructional system in terms of expression of opinions, which were considered $100 \%$ (see Table III).

TABLE III: ACCORDING TO THE DETAILS ABOUT THE INTERACTION BETWEEN THE STUDENTS ON THE INSTRUCTIONAL SYSTEM (EXPRESSION OF

\begin{tabular}{ccc}
\multicolumn{3}{c}{ OPINIONS) } \\
\cline { 2 - 3 } Detail & \multicolumn{2}{c}{$n=30$} \\
Number & $\%$ \\
\hline (Person) & $\%$ \\
Interaction between the students on the instructional system \\
(expression of opinions) \\
Week 1 \\
Week 3 & 28 & 93.3 \\
Week 5 & 27 & 90 \\
\hline
\end{tabular}

According to the details about the submission of assigned tasks, it was found out that, in Week 1, 30 students from the sample group submitted their assigned tasks, which were considered $100 \%$. In Week 3, 30 students from the sample group submitted their assigned tasks, which were considered $100 \%$. In Week 5, 30 students from the sample group submitted their assigned tasks, which were considered $100 \%$ (see Table IV-Table V).

TABLE IV: ACCORDING TO THE DETAILS ABOUT THE SUBMISSION OF ASSIGNED TASKS

\begin{tabular}{ccc}
\hline \multirow{2}{*}{ Detail } & \multicolumn{2}{c}{$n=30$} \\
\cline { 2 - 3 } & $\begin{array}{l}\text { Number } \\
\text { (Person) }\end{array}$ & $\%$ \\
\hline Submission of assigned tasks & 30 & 100 \\
Week 1 & 30 & 100 \\
Week 3 & 30 & 100 \\
Week 5 & & \\
\hline
\end{tabular}

TABLE V: ACCORDING TO THE DETAILS ABOUT THE SCORES OF LEARNING BEHAVIORS OF THE SAMPLE GROUP IN TERMS OF QUALITY OF WORKS

\begin{tabular}{|c|c|c|c|c|c|c|}
\hline $\begin{array}{c}\text { Variance } \\
\text { Source }\end{array}$ & $d f$ & SS & MS & $\boldsymbol{F}$ & Sig. & \\
\hline $\begin{array}{l}\text { Each } \\
\text { measure- } \\
\text { ment }\end{array}$ & 1.00 & $\begin{array}{l}19.2 \\
6\end{array}$ & $\begin{array}{l}19.2 \\
6\end{array}$ & $\begin{array}{l}33.3 \\
9\end{array}$ & .00 & $\begin{array}{l}\text { Week } 5> \\
\text { Week } 1 \\
(\text { sig }=0.000)\end{array}$ \\
\hline Error & $\begin{array}{l}29.0 \\
0\end{array}$ & $\begin{array}{l}16.7 \\
3\end{array}$ & .577 & & & $\begin{array}{l}\text { Week } 5> \\
\text { Week } 3 \\
(\text { sig }=0.039)\end{array}$ \\
\hline
\end{tabular}

Mauchly's W $=0.810$ sig $=.052$

According to the details about the scores of learning behaviors of the sample group in terms of quality of works, the researcher conducted an analysis to compare the students' learning development by analyzing the repeated measure ANOVA. In this process, the researcher examined the basic agreements concerning compound symmetry by conducting the Mauchly's Test of Sphericity. According to the 3 measurements, the statistical value of Mauchly's W totaled 0.810 , and the value of sig totaled .052 , which demonstrated that the variance had the characteristic of compound symmetry. Therefore, the researcher read the results of the test regarding different learning development of the students in 3 weeks from the $\mathrm{F}$ from Greenhouse-Geisser. The results showed that $\mathrm{F}$ totaled 12.700 and sig totaled .000 . Thus, it could be concluded that the scores from the measurements in 3 weeks had at least 1 pair that was different with the statistical significance of .05. Hence, the researcher conducted the pairs check by the method of Bonferoni and realized that the students' scores of works in Week 5 were higher than in Week 1 with the statistical significance of .05 . Also, the scores of works in Week 5 were higher than in Week 3 with the statistical significance of .05 .

According to the details about the scores of learning behaviors of the sample group in terms of quality of works, the researcher conducted an analysis to compare the students' learning development by analyzing the repeated measure ANOVA. In this process, the researcher examined the basic agreements concerning compound symmetry by conducting the Mauchly's Test of Sphericity. According to the 3 measurements, the statistical value of Mauchly's W totaled 0.868 and the value of sig totaled .138 , which demonstrated that the variance had the characteristic of compound symmetry. Therefore, the researcher read the results of the test regarding different learning development of the students in 3 weeks from the $\mathrm{F}$ from Greenhouse-Geisser. The results showed that $\mathrm{F}$ totaled 10.172 and sig totaled .000 . Therefore, it could be summed up that the scores from the measurements in 3 weeks had at least 1 pair that was different with the statistical significance of .05 . Hence, the researcher conducted the pairs check by the method of Bonferoni and realized that the students' scores of works in Week 5 were higher than in Week 1 with the statistical significance of .05 . Also, the scores of works in Week 5 were higher than in Week 3 with the statistical significance of .05 (see Table VI-Table VII).

TABLE VI: ACCORDING TO THE DETAILS ABOUT THE SCORES OF LEARNING BEHAVIORS OF THE SAMPLE GROUP IN TERMS OF QUALITY OF WORKS

\begin{tabular}{|c|c|c|c|c|c|c|}
\hline $\begin{array}{c}\text { Variance } \\
\text { Source }\end{array}$ & $d f$ & SS & MS & $F$ & Sig. & Note \\
\hline $\begin{array}{l}\text { Each } \\
\text { measure- } \\
\text { ment }\end{array}$ & 1.00 & $\begin{array}{l}14 . \\
01\end{array}$ & $\begin{array}{l}14 . \\
01\end{array}$ & $\begin{array}{l}17 . \\
30\end{array}$ & .00 & $\begin{array}{l}\text { Week } 5> \\
\text { Week } 1 \\
(\operatorname{sig}=0.001)\end{array}$ \\
\hline Error & $\begin{array}{l}29.0 \\
0\end{array}$ & $\begin{array}{l}23 . \\
48\end{array}$ & $\begin{array}{l}.81 \\
0\end{array}$ & & & $\begin{array}{l}\text { Week } 5> \\
\text { Week } 3 \\
(\text { sig }=0.032)\end{array}$ \\
\hline
\end{tabular}

Mauchly's W = 0.868 sig $=.138$

According to the results of the analysis of the sample group's posttest scores, the mean $(\tilde{x})$ totaled 25.93 and the SD totaled 3.49. There was 1 student whose posttest score was in the very low range of $0-54 \%$, which was considered $3 \%$. There were 3 students whose posttest scores were in the moderate range of $66-75 \%$, which were considered $10 \%$. There were 7 students whose posttest scores were in the good range of $76-85 \%$, which were considered $23 \%$. Finally, there were 19 students whose posttest scores were in the very 
good range of $85-100 \%$, which were considered $64 \%$.

TABLE VII: ACCORDING TO THE RESULTS OF THE ANALYSIS OF THE SAMPLE GROUP's POSTTEST SCORES

\begin{tabular}{|c|c|c|c|c|c|}
\hline \multirow[b]{2}{*}{ Detail } & \multirow[b]{2}{*}{$\begin{array}{c}\text { Full } \\
\text { score }\end{array}$} & \multirow[b]{2}{*}{$\begin{array}{l}\text { Mean } \\
\tilde{x}\end{array}$} & \multirow[b]{2}{*}{ S.D. } & \multicolumn{2}{|c|}{$n=30$} \\
\hline & & & & $\begin{array}{c}\text { No. } \\
\text { (person) }\end{array}$ & $\%$ \\
\hline Posttest & 30 & 25.93 & 3.49 & & \\
\hline $0-54 \%$ & & & & 1 & 3 \\
\hline $55-65 \%$ & & & & 0 & 0 \\
\hline $66-75 \%$ & & & & 3 & 10 \\
\hline $76-85 \%$ & & & & 7 & 23 \\
\hline $\begin{array}{l}86 \\
-100 \%\end{array}$ & & & & 19 & 64 \\
\hline \multicolumn{4}{|c|}{ Total } & 30 & 100 \\
\hline
\end{tabular}

\section{DisCusSION}

From the study, analysis and congregation of the sample group's information, the documents, interviews of experts, study of the model implementation's result and suggestions from knowledgeable individuals - the research concluded the result on the study: effect of using online active instructional model to enhance learning behaviors of undergraduate students - as follows.

From the result study of model implementation, the average score of learning behavior in the sample groups after class has the score, under the rubric evaluation criteria, in the $1^{\text {st }}$ trial, the $3^{\text {rd }}$ trial and the $5^{\text {th }}$ trial with statistical difference at the level of 0.05 . When considered the achievement post-learning, the majority of the sample group's score was in the 'High' range. The surveys done by the sample group, on their opinions towards online active instructional model to enhance learning behavior of undergraduates, demonstrated many opinions on the model implementation in an overall picture.

The initial study revealed online active instructional model to enhance learning behavior of undergraduates could actually enhance undergraduates' learning behaviors. This is because within the online active instructional model to enhance learning behavior of undergraduates, there are 5 steps as follows.

Step 1: researching. It was an activity that opened opportunities for learners. They were able to learn content from online lessons as designated by a lecturer in each week through e-document. Learners could do additional research from what was designated by the lecturer. It would stimulate learners to have more desires to learn. This corresponded with online active instructional model to enhance learning behaviors of undergraduate students; in terms of learners, the lesson's content, the system of learning, learner-centric teaching, and learning behavior adjustment procedures. Also, the procedures within the researching step could modify learning behaviors of learners on their part. Be it in terms of accessibility to the learning system (class attendance), and duration of the learning system. The behaviors in accessing to learning system (class attendance) could measure behaviors from the number of learners logged in each week. From observation on learning behavior, it appeared that the number of learners logged into the system increased as more weeks passed. The behavior in terms of duration in accessing the learning system could measure the behavior of learners. This is based from the duration learners clocked into the learning system each week. From the observation on learning behavior, it appeared that duration learners spent in accessing the learning system decreased as weeks passed. This is because they have become more familiar with the learning system.

The $1^{\text {st }}$ step in the procedure: the research step was an activity that opened opportunities for learners to learn through practices. The activity was the chance for learners to receive information and experiences through self-learning. This would create meaningful self-learning, consistent with the concept, learning by doing by John Dewey [5]. It stated: learning occurred through actions. It could be actions taken for an activity, or interactions taken with environment that were meaningful to themselves. It then became knowledge. Also, the $1^{\text {st }}$ step of researching also trained learners for research works and self-study [6].

The $2^{\text {nd }}$ step: connecting problems. This was an activity required learners to use knowledge from the $1^{\text {st }}$ step of researching to make connections in answering problems set by lecturers on Sticky Note Online. The purpose was to stimulate learners' desire and enthusiasm to seek answers for the lecture's question. This would connect components of online active instructional model to enhance learning behaviors of undergraduates. This would be done in terms of learners' role, lessons' content, learning system, learner-centric teaching and modification of learning behaviors. The procedure, in the step of connecting problems, could help adjust learning behavior of learners on their part, on learners' interaction with lecturers within the learning system, and submission of works as assigned. The behaviors concerning learners' interaction with lecturers on the learning system could measure its behaviors from the quality points of learners' answers. Observation of learning behaviors revealed that the quality points within learners' works increased in the following weeks. Also, the learners' work submission behaviors could be measured from the number of learners submitting as assigned by lecturers. Results from learning behavior observation revealed learners submitted assignments to lecturers more often in the following weeks.

The operation in the $2^{\text {nd }}$ step, connecting problems, opened opportunities for learners to make connections from the existing knowledge to answering questions set by a lecturer. This was consistent to the concept of that there must be continuity within experiences. As incidents happen and we reacted to various experiences we encounter, learners must always adapt. Each experience thus must have continuous relationship. Knowledge obtained from an experience would become a tool necessary to comprehend a following situation. Also, the activity from the $2^{\text {nd }}$ step of connecting problems trained learners to connect existing knowledge with new experiences.

The $3^{\text {rd }}$ step: brainstorm, was a mandatory step for learners. Summarization of lessons learnt from learning activities set by lecturers, with learners collaborated among themselves on Google Document to gather all information learnt in its completion. This was also for learners to exchange knowledge with the members of the same group. Such was connected with components of online active instructional 
model to adjust learning behaviors of undergraduates; in terms of learners' role, learning system, lessons' content, learners-centric teaching, communication through technology and procedures of learning behaviors' adjustment Also, activities from the brainstorming step helped adjust learners' learning behaviors; and in terms of learners, there were interactions with lecturers on the learning system, interactions between learners on the learning system and submission of assignments. On behaviors, learners had interactions with learners on the learning system; a measurement could be made from answers' quality points of learners' individual assignment. From learning behaviors' observation, it appeared that the answers' quality points in learners' assignment increased in the following weeks. Interactive behaviors among learners on the learning system could be measure from the quality points. From learning behavior observation, it appeared that the answers' quality points in learners' individual assignment increased in the following weeks. Learner's assignment submission behaviors could be behaviorally measured from the number of learners who submitted assignments as designated by lecturers. Observations on the learning behaviors showed that learners who submitted works as assigned by lecturer increased in numbers in the following weeks.

The procedure in the $3^{\text {rd }}$ step of brainstorm was an education activity that is learners-centric. Learners would have freedom, got to be themselves and possessed high self-control. Learners would be the active agent, and thought about actions taken. There would be procedures of thinking, analysis and congregating, which was consistent to concept [7]-[9] on active learning. It said, active learning with activities for learners to take actions using various skills for development of critical thinking, such as problem solving and analysis, should replace passive lessons - where lecturers were the only active agent telling learners stories. Learners must have interactions among each other to create learning experiences. Activities of Step 3, brainstorm, was working by segregating into small groups. Teamwork creates better learning behaviors.

Step 4: observation. It was a step where learners had to study results of other groups' brainstorm work through Google document. Lecturers would share the link through the social network of Facebook. Leaners would learn the results of other groups' brainstorm work, so they may understand lessons from a broader perspective. This would increase new learning experiences for learners, connected to components of online active instructional model to adjust learning behaviors of undergraduates; be it in terms of learners' role, lessons' content, learning system, learner-centric education and learning behaviors adjustment behaviors. Operations within the step of observation could adjust learning behaviors for learners on their part, either on the accessing of learning system (class attendance), and duration spent on the learning system. The behavior of accessing into learning system (class attendance) could be measured from the number of learners logged into the system each week. From observation of learning behaviors, it appeared that the number of learners logged into the learning system increased as weeks passed. Behaviors in terms of duration on learning system could be measured from the duration learners used for learning system each week. From the learning behaviors observation, it appeared that the duration learners spent on learning system decreased in the following week. This was because learners become more familiar with the learning system.

That is, the operation in the 4step of observation was an educational activity that provided chances for learners to explore the results of other groups' brainstorm. Learners would be able to reflect to their own group's brainstorm. With analytical procedure, congregation which were consistent with concepts of that active learning must stimulate thoughts, analysis and criticism to enhance self-built knowledge. This included learners' skill of applications, and procedures created from learners' exposure or interactions, which led to acceptance or absorbance of various issues into their thoughts. Also to adjust the existing knowledge to fit with the new knowledge learners chanced upon.

Step 5, reflection. This was an activity which learners must reflect from online active learning designated by lecturers on Google Drive, and was a lesson which learners must seek for meaning and comprehend it by themselves. Learners must conclude ideas. Or in another sense, this changed learners from being a passive listener to active learners participating in activities, seeking for knowledge as set by the lecturer. This connected with components from online active learning model to adjust learning behavior of undergraduates. In terms of learners, there would be learning system, lessons' content, education which was learners-centric, and learning behavior adjustment procedures, and reflect the learners' learning. The operation within the reflection step could adjust learning behavior of learners on their part. As for learners who interacted with lecturers on the learning system, and for assignments to be submitted as designated. In terms of learners' behaviors, they had interactions with lecturers on learning system. One could measure the behavior from learners' score on reflection quality. From the learning behaviors' observation, it appeared that learners' scores on quality of reflection kept increasing in the following weeks. Learners' work submission behaviors as assigned could be measures from the number of students who submitted work as requested by lecturers. Observation of learning behaviors indicated that the numbers of learners who submitted the assignments on time kept increasing each week.

Operations in the $5^{\text {th }}$ step: reflection, was an activity focused on the writing skills. Writing cleared up the thoughts of learners. Also, the goal of writing within active learning was to provide learners a chance to explore their own thoughts on visions, or issues studied to nurture the concept further intellectually. This was consistent with the concept of [10] and [11] on reflection. It was an activity providing learners a chance to explore themselves, in terms of knowledge, intention and values of learning - for their own understanding. After each lesson, learners were to write a conclusion of lessons learnt, expressed opinions and analysis to respond to lecturers' teaching. From discussion of research's result on utilization of online active instructional model to enhance learning behavior of undergraduates, there was consistency with relevant researches. That is, crucial factors affecting learners' learning behaviors was lessons that promoted learners to take actions by self-learning, as well as activities that stimulate learners for their interests in learning 
[12]. Furthermore, it was also consistent with a research about development of integrated learning model: through an active learning activity to create knowledge, and capability in creatively solving for undergraduates of teaching majors in public universities. This was done by Ms.Naowanit Songkram (2555 B.E.), and electronics media utilization of undergraduates, King Mongkutt University of Technology, Thonburi, by Namfon Pitaksapaisal (2548 B.E.) [13]. The researcher discovered that learning model which enhance learning behaviors shared some characteristics. The characteristics were: contained activities that stimulate learners to desire learning, having learners taking actions in the activity, and the use of tools in lessons to attract learners' interests. Afterwards, there were also interactions between learners to stimulate the adjustment of their learning behaviors.

\section{Suggestions On Result's UAGE}

The online active instructional model should be used to enhance learning behaviors of learners. Research's result indicated that, as time passed, learners would use less time to learn as they gain familiarity. Therefore, even if online active learning caused learner a lot of time initially, the duration would eventually decrease. Other active learning behaviors would also increased, such as accessing the learning system (class attendance), interactions among learners, interactions between learners and lecturers, work submission as assigned, and academic accomplishment post-lesson.

Learners' opinions indicated that supporting tools for brainstorm, and online collaboration such as Google Document and Sticky Note Online helped learners to be work-enthusiastic. It could be used for future application of other works. Thus, for the management of online active learning, the lecturer must use supporting tools for brainstorm and learners' collaboration.

Conditions in implementing the model, lecturers may adjust lesson's steps. There was no need to conduct it in sequence. This depended on the context, content and the expected group using it - for the maximum benefits in implementing online active instructional model to enhance learning behaviors of undergraduates.

\section{SugGeStions fOR NeXT RESEARChES}

Active learning is beneficial. It allows learners to gain understanding in the taught visions correctly and deeply. The learning will last, through learning activities organized and interactions among friends and lecturers. This gives a chance to develop social skills, allowing them to have fun learning, to have more interests and become more determine to learn. In the researcher's opinion, for future experiments, lessons that support active learning should be designed to develop learners' learning capacity.

Learning behavior was what learners demonstrated as the interests they have towards the lessons. Learners would take parts in conducting a number of activities in lessons. As a result, learners will learn and comprehend subjects conveyed from lecturers. The researcher's opinion is that, for the next experiment, a lesson that can stimulate desirable learning behaviors of learners should be designed. This is for the benefits in learning.

\section{REFERENCES}

[1] J. Sweller, "The worked example effect and human cognition: Learning and instruction," Educational Technilogies, vol. 2, no. 1, 2006.

[2] J. Renner and M. Abraham, "The necessity of each phase of the learning cycle in teaching high school physics," Journal of Research in Science Teaching, vol. 25, no. 1, pp. 39-58, 2008.

[3] A. K. Soonthorn. (2007). The Principal Plan of Using ICT to Develop Education. [Online]. Available: http:// www.moe.go.th.

[4] S. Sarasuphab, "Development of an online social network learning model utilizing situated learning theory to enhance intercultual awareness of foreign language learners," Thesis of graduate studies, educational technology and communication division, Division of teaching, Major of teaching, Chulalongkorn University, 2010.

[5] M. Lorenzen, "Active learning and library instruction," Illinois Libraries, vol. 83, no. 2, pp. 19-24, 2001.

[6] T. Kammanee, The Art of Teaching, the Knowledge to Create Effectively Learning Procedure, Bangkok: Chulalongkorn University publications, 2001

[7] S. F. Schomberg, "Strategies for active teaching and learning in university classrooms," Minneapolis, University of Minnesota, p. 112, 1986.

[8] B. Wattana, “Active learning," Academic Journal, vol. 6, no. 9, pp. 30-34, 2003.

[9] P. Dechsri, "Active learning: How could it be done," Scientific, Mathematical and Technological Study, vol. 30, no. 116, pp. 53-55 2002.

[10] S. Tunthong, "Development of learning's evaluation model according to the learners' true state," Thesis of a bachelor degree, division of examinations and education's evaluation, Sri Nakarinviroth University, 2002

[11] N. Songkram, "The development of blended learning model with active learning of knowledge construction and creative problem solves ability for undergraduate students," Research of Annual Governmental Expenditure's Assistance, Chulalongkorn university, vol. 52, no. 1, 2012.

[12] P. Nakklay, "Factors influening self-directed study of high school students under the jurisdiction of chachoengsao educational services area of ice 1 in chachoengsao province," Thesis of graduate studies. Division of Education's Research, Education Major, Ramkamhang University, 2007.

[13] N. Pitakpaisal, "A study of relationship between learning behavior and electronic media utilization of undergraduate atudent at king mongkut's University of techology thonburi," Thesis of a master degree, division of teaching's technology, major of education's industry and technology, King Mongkutt University Technology of Thonburi, 2005.

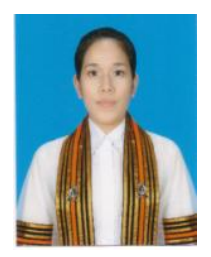

Jirapha Autthaporn was graduated from master of teaching. She is majored in educational technology and communication. She is a teaching faculty of Taksin University. And she graduated from the master of teaching, majored in educational technology and communication, Teaching Faculty, Chulalongkorn University.

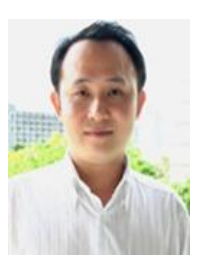

Prakob Koraneekij was born in Chonburi Province, Thailand. In 1997, he received the Ph.D. degree in educational technology and communication program, Faculty of Education, Chulalongkorn University. From 1988 to 2002 he was teaching secondary school student technology class in Chulalongkorn University Demonstration Secondary School. Afterwards, in 2003 he was an educational technology lecturer in the Department of Educational Technology and Communication at the Chulalongkorn University. During that time he also conducted the research on the electronic portfolios for educational instruction. His research interest is in an effect of levels of learning ability and types of feedback in electronic portfolio on learning achievement of students in electronic media production for education subject and development of blended e-learning model using online interactive reflective learning logs to enhance faculty of education students' inquiring mind and retention at Chulalongkorn University. 